\title{
Evaluating the Impact of Road Grade on Simulated Commercial Vehicle Fuel Economy Using Real-World Drive Cycles
}

\section{Sean Lopp, Eric Wood, and Adam Duran}

National Renewable Energy Laboratory

CITATION: Lopp, S., Wood, E., and Duran, A., "Evaluating the Impact of Road Grade on Simulated Commercial Vehicle Fuel Economy Using Real-World Drive Cycles," SAE Technical Paper 2015-01-2739, 2015, doi:10.4271/2015-01-2739.

\begin{abstract}
Commercial vehicle fuel economy is known to vary significantly with both positive and negative road grade. Medium- and heavy-duty vehicles operating at highway speeds require incrementally larger amounts of energy to pull heavy payloads up inclines as road grade increases. Non-hybrid vehicles are unable to recapture energy on descent and lose energy through friction braking. While the on-road effects of road grade are well understood, the majority of standard commercial vehicle drive cycles feature no road grade requirements. Additionally, the existing literature offers a limited number of sources that attempt to estimate the on-road energy implications of road grade in the medium- and heavy-duty space.
\end{abstract}

This study uses real-world commercial vehicle drive cycles from the National Renewable Energy Laboratory's Fleet DNA database to simulate the effects of road grade on fuel economy across a range of vocations, operating conditions, and locations. Road grade data is appended to real-world drive cycles using the United States Geological Survey's 1/3 arc-second digital elevation model. Realworld drive cycles are then paired with vocation-specific vehicle models and simulated with and without grade. Percentage fuel use increase due to grade is presented, and variation in fuel consumption due to drive cycle and vehicle characteristics is explored through graphical and statistical comparison. The results of this study suggest that road grade accounts for $1 \%-9 \%$ of fuel use in commercial vehicles on average and up to $40 \%$ on select real-world drive cycles.

\section{Introduction}

Understanding the drivers of fuel use in commercial applications is a necessary step in designing more efficient engines, powertrains, and vehicles. Existing studies have demonstrated incremental fuel use resulting from commercial vehicle operation on grades ranging from $10 \%-30 \%[\underline{1}, \underline{2}, \underline{3}, \underline{4}, \underline{5}, \underline{6}, \underline{7}]$. While insightful, these studies generally focused on specific vocations (most commonly Class 8 line haul) and were often limited to a small number of real-world drive cycles. The literature lacks an aggregate quantification of the impact of road grade on fuel use in commercial applications over a wide range of operating conditions. This paper seeks to characterize the increase in fuel use incurred due to road grade through large-scale simulation of commercial vehicle operation using real-world drive cycles and road grade data.

Specifically, this analysis will:

- $\quad$ Present global positioning system (GPS) drive cycle data from four real-world commercial vocations

- $\quad$ Append road grade to GPS drive cycles using a digital elevation model (DEM) of the United States

- Develop conventional and hybrid powertrain models for each of the four commercial vocations

- $\quad$ Simulate fuel economy for all GPS drive cycles with and without road grade

- Analyze the impact of drive cycle, powertrain, and mass on simulated fuel economy.

\section{Methodology}

\section{Real-World Drive Cycles}

Real-world drive cycles for this analysis are sourced from the National Renewable Energy Laboratory's (NREL's) Fleet DNA database of commercial vehicle activity [ $[$ ]. The data examined as part of this study are sourced from multiple commercial vehicle fleets operating across the United States, encompassing a variety of geographic regions and transportation networks. GPS measurements of vehicle position and velocity are collected via a combination of telemetric and onboard data logging devices and are filtered to produce 1-hertz speed profiles suitable for powertrain simulation [9]. In total, 125,469 miles of real-world driving were utilized in this analysis. Table 1 summarizes drive cycle characteristics by vocation for the data used in this analysis. 
Table 1. Real-world drive cycle characteristics by vocation

\begin{tabular}{|l|l|l|}
\hline Vocation & $\begin{array}{l}\text { Vehicle } \\
\text { Count }\end{array}$ & $\begin{array}{l}\text { Distance } \\
(\mathrm{mi})\end{array}$ \\
\hline Beverage Delivery & 57 & 43,371 \\
\hline Parcel Delivery & 43 & 14,002 \\
\hline Refuse Pickup & 41 & 29,931 \\
\hline Bus & 212 & 38,164 \\
\hline
\end{tabular}

\section{Appending Road Grade}

The United States Geological Survey's (USGS's) 1/3 arc-second DEM was used as the basis for appending road grade to GPS data in this analysis. The 1/3 arc-second DEM forms an approximate 10 -meter $\times 10$-meter grid across the United States and is the finest resolution map with complete national coverage currently available from the USGS. Figure 1 shows a graphical representation of the national map. This DEM is a composite of several regional data sources digitally stitched together to form a seamless elevation map of the United States. Regional elevation datasets are generated using a variety of methods, including electronic image correlation, manual profiling, laser illuminated detection and ranging (lidar) digital camera correlation, and other remote sensing techniques.

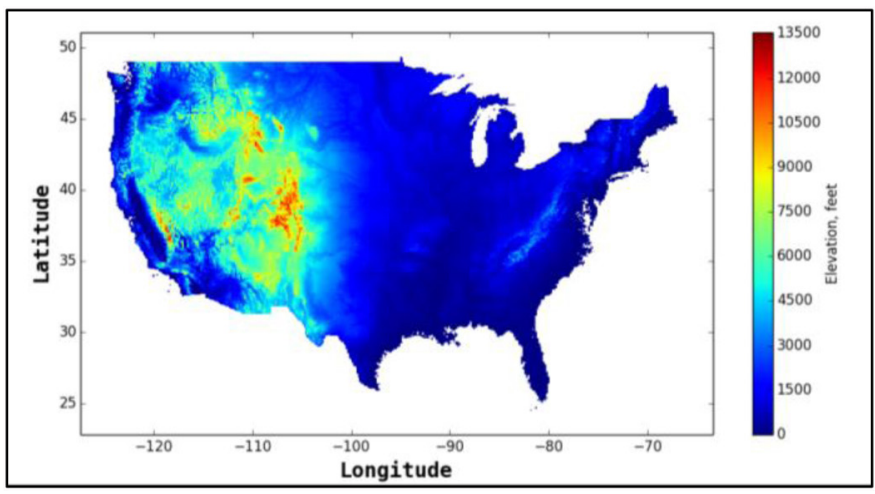

Figure 1. United States elevation map utilizing USGS 1/3 arc-second DEM

As part of NREL's standard routine for processing vehicle GPS data, elevations from the USGS DEM are matched to each recorded point in a GPS trace. The raw elevation data are filtered, smoothed, and differentiated to calculate an estimate of road grade corresponding to second-by-second vehicle speed. This process was calibrated in 2014 to a commercially available road-grade database with an absolute root mean square (RMS) error of $1.48 \%$ road grade [1]].

Figure 2 presents the empirical cumulative distribution of absolute road grade for the real-world drive cycles, separated by vocation. The steepest curves have a high percentage of points with low grade. For example, $80 \%$ of the data points associated with the beverage delivery vehicles have less than $1 \%$ absolute grade. Forty percent of the bus profile data points have an absolute grade greater than $2 \%$. The difference in grade profiles by vocation is a result of collecting data from providers operating in different locations. For example, a large portion of the bus data was collected from a school district in
Colorado, whereas the majority of refuse pickup data was collected in Indianapolis. A further study, requiring additional data collection, might compare different vocations operating at the same location.

\section{Fuel Economy Simulations}

Vehicle powertrain modeling was performed using NREL's Future Automotive Systems Technology Simulator (FASTSim) [11- 12$]$. FASTSim is a vehicle simulation tool developed by NREL to evaluate the impact of various technologies on vehicle performance, cost, and utility in conventional and advanced technology powertrains. FASTSim calculates the power necessary to meet a given speed trace while considering component limitations and system losses. It includes control strategies to account for hybrid electric and hydraulic hybrid medium- and heavy-duty vehicles. In particular, grade is included in the calculation of tractive power required to meet a drive cycle.

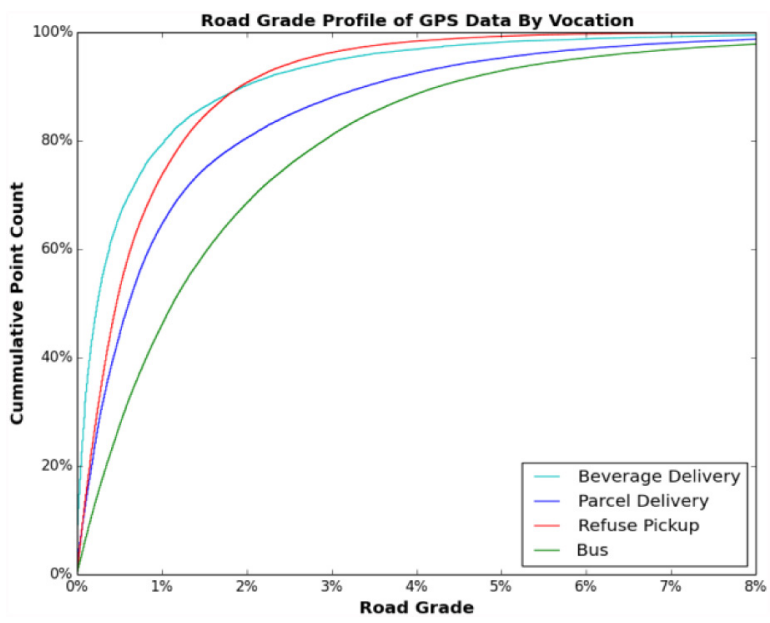

Figure 2. Cumulative density function of road grade appended to real-world drive cycles by vocation

Each set of vocation-specific drive cycles was paired with a representative vehicle model. For each vocation and vehicle model, an empty payload (curb weight) and full payload (gross vehicle weight rating [GVWR]) were considered. Table 2 outlines some of the key model parameters for each vehicle model. In particular, it is important to note that the power-to-weight ratio differs for each vocation, with the bus having the lowest power-to-weight ratio at curb weight. The vehicle models in FASTSim were validated to fuel use data from a number of dynamometer tests and fuel use collected from on-road data.

Table 3 presents fuel economy simulation results by vehicle model for the three components of the California Air Resource Board heavy heavy-duty diesel truck (HHDDT) drive cycle. The creep component refers to a section of low-speed, start-stop driving. The cruise section refers to high-speed driving consistent with what might be seen on a freeway. The transient section contains segments of high-speed driving and segments of deceleration, stopping, and acceleration. This paper will look at relative fuel use penalties, specifically the increase in fuel use for each vocation when accounting for grade. 
Table 2. FASTSim key model parameters

\begin{tabular}{|l|l|l|l|l|l|}
\hline Vocation & $\begin{array}{l}\text { Curb } \\
\text { Mass } \\
(\mathrm{kg})\end{array}$ & $\begin{array}{l}\text { GVWR } \\
\text { Mass-Full } \\
(\mathrm{kg})\end{array}$ & $\begin{array}{l}\text { Engine } \\
\text { Power } \\
(\mathrm{kW})\end{array}$ & $\begin{array}{l}\text { Power-to- } \\
\text { Weight } \\
\text { Ratio at } \\
\text { Curb } \\
\text { Weight } \\
(\mathrm{kW} / \mathrm{kg})\end{array}$ & $\begin{array}{l}\text { Power-to- } \\
\text { Weight } \\
\text { Ratio at } \\
\text { GVWR } \\
(\mathrm{kW} / \mathrm{kg})\end{array}$ \\
\hline $\begin{array}{l}\text { Beverage } \\
\text { Delivery }\end{array}$ & 5,157 & 15,740 & 212 & 0.041 & 0.013 \\
\hline $\begin{array}{l}\text { Parcel } \\
\text { Delivery }\end{array}$ & 4,309 & 6,803 & 223 & 0.052 & 0.033 \\
\hline $\begin{array}{l}\text { Refuse } \\
\text { Pickup }\end{array}$ & 6,000 & 11,793 & 275 & 0.046 & 0.023 \\
\hline Bus & 10,303 & 14,968 & 209 & 0.020 & 0.014 \\
\hline
\end{tabular}

$\underline{\text { Table } 3}$ presents a baseline from which this relative fuel use penalty can be understood. For example, while the refuse pickup vehicle may have a lower relative fuel penalty, it is still the least fuel efficient vehicle under stop-and-go driving conditions.

Table 3. Simulated fuel economy over standard drive cycles assuming curb mass

\begin{tabular}{|l|l|l|l|}
\hline Vocation & $\begin{array}{l}\text { HHDDT } \\
\text { Creep } \\
(\mathrm{mpg})\end{array}$ & $\begin{array}{l}\text { HHDDT } \\
\text { Cruise } \\
(\mathrm{mpg})\end{array}$ & $\begin{array}{l}\text { HHDDT } \\
\text { Transient } \\
(\mathrm{mpg})\end{array}$ \\
\hline $\begin{array}{l}\text { Beverage } \\
\text { Delivery }\end{array}$ & 3.13 & 6.90 & 8.87 \\
\hline $\begin{array}{l}\text { Parcel } \\
\text { Delivery }\end{array}$ & 2.44 & 9.59 & 9.98 \\
\hline $\begin{array}{l}\text { Refuse } \\
\text { Pickup }\end{array}$ & 1.33 & 5.92 & 6.18 \\
\hline Bus & 2.66 & 7.60 & 6.69 \\
\hline
\end{tabular}

Each vehicle model and weight pair was simulated across the set of corresponding vocation-specific real-world drive cycles with and without grade. Fuel use and required power (attributed to aerodynamic drag, acceleration, rolling resistance, and ascent) from real-world drive cycles were recorded and aggregated by vehicle trip (defined as the time between key-on and key-off). Average and RMS grades were also calculated for each trip.

\section{Results}

\section{Impact of Grade}

Required power and fuel use generally increased when vehicles were ascending and decreased when descending. As an example, Figure 3 shows how required ascent power increases on segments of positive grade and decreases on negative grade. At the top of a hill, the cumulative energy attributed to ascent is a significant portion of the total. On the other hand, during descent energy is added to the system. Over the entire trip-which has a net elevation change close to zero-the total cumulative energy due to ascent and descent is close to zero. However, trips with net energy attributed to grade close to zero can still have a significant fuel penalty due to grade. The increase in required power due to ascent can force the engine into a less efficient operating point. Increases in fuel consumption can then be attributed to the engine operating less efficiently compared to a zero grade trip where the same speed is maintained but power is more efficiently transferred from the engine.

\section{Results by Vocation}

For each trip, fuel use with and without grade was used to calculate a percent penalty in fuel use due to road grade. Table 4 summarizes the simulation results. The magnitude of the fuel use penalty depends most on the grade profile of the drive cycles associated with each vocation. Therefore, the bus penalty is larger than the refuse truck penalty because the bus drive cycles have higher average RMS grade content. Analysis of variance was used to test whether or not the increase in fuel use was statistically significant for each vocation relative to the variation in fuel use across trips. For each vocation, adding grade was significant.

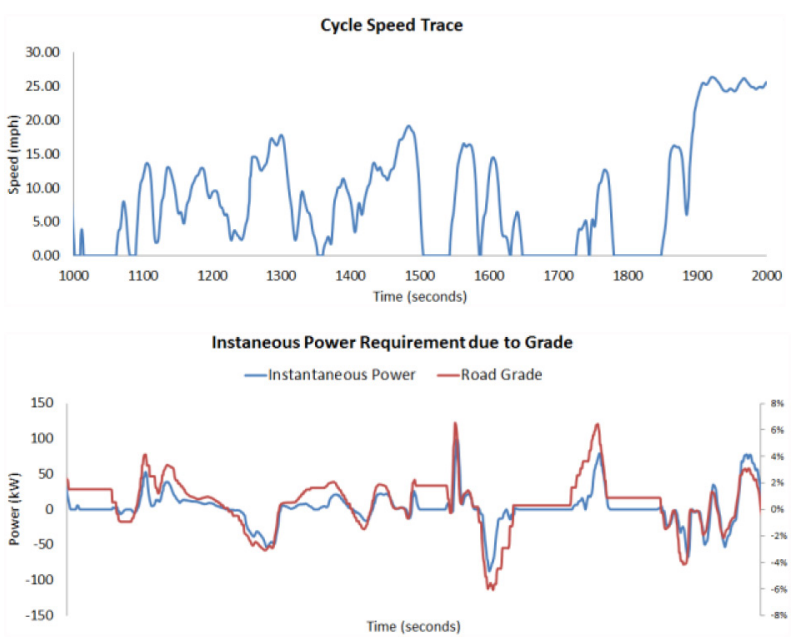

Figure 3. Influence of grade on energy use for a portion of a real-world bus cycle

Two measurements of grade were considered at the trip level: average and RMS. Across all vocations, trips with a positive average grade (corresponding to a net elevation gain) had a larger fuel use penalty when accounting for grade. In Figure 4, for example, bus fuel use increased by upwards of $40 \%$ for trips with an average grade of $1 \%$.

Table 4. Simulation results by vocation

\begin{tabular}{|l|l|l|}
\hline Vocation & Avg. RMS Grade & $\begin{array}{l}\text { Avg. Fuel Use } \\
\text { Penalty }\end{array}$ \\
\hline Beverage Delivery & $1.2 \%$ & $0.8 \%$ \\
\hline Parcel Delivery & $1.7 \%$ & $1.4 \%$ \\
\hline Refuse Pickup & $1.2 \%$ & $0.0 \%$ \\
\hline Bus & $2.8 \%$ & $9.0 \%$ \\
\hline
\end{tabular}

Additionally, trips with small average grade can still have significant RMS grade and fuel penalties. Figures 5 and $\underline{6}$ compare fuel use between vocations by isolating trips with roughly net-zero elevation change, or equivalently distance-averaged absolute grade between $0.0 \%$ and $1.0 \%$. RMS grade is used as an indication of the average magnitude in grade across a trip. RMS grade distinguishes between a trip with no climbs or descents and a trip with equal amounts of climbs and descents. Figure 5 suggests that for RMS grade close to 
$3 \%$ average fuel penalties range from $4 \%$ to $15 \%$ by vocation. However, for the few trips with very large RMS grade (above $6 \%$ ), penalties can be above $30 \%$ of fuel use.

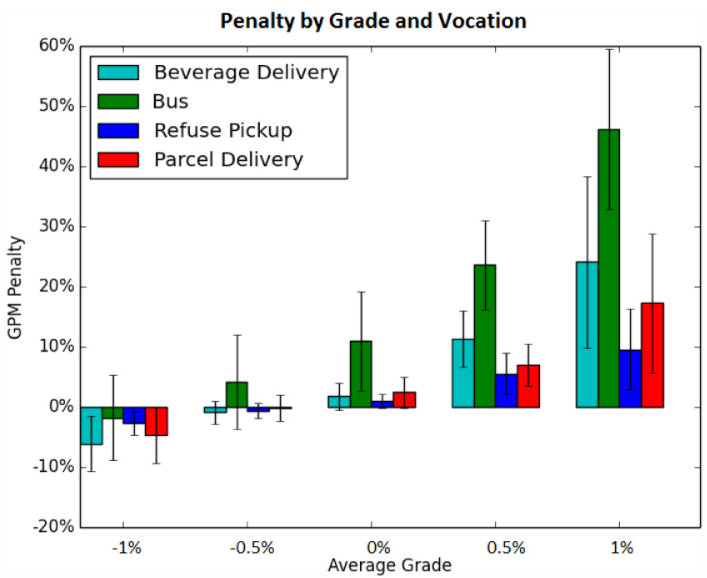

Figure 4. Gallon per mile (GPM) fuel use penalty increases for trips with a positive average grade, corresponding to a net gain in elevation.

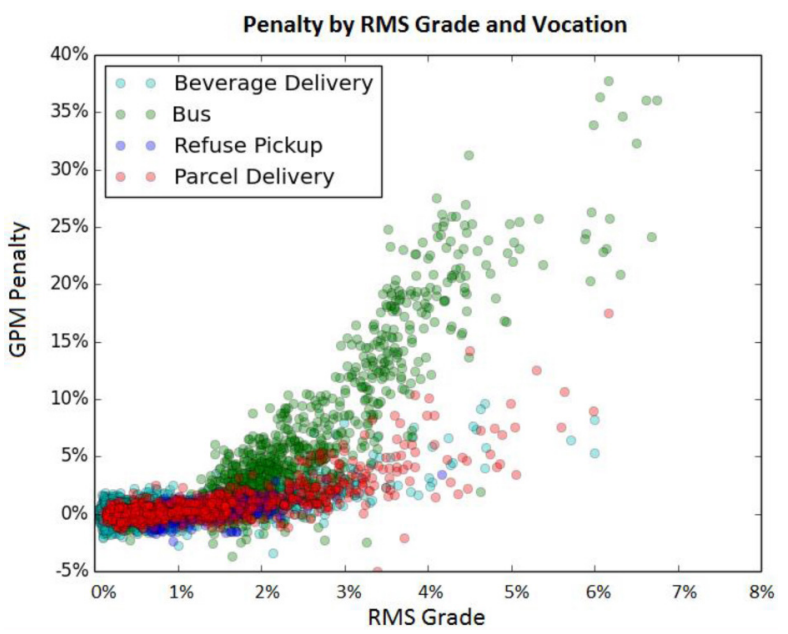

Figure 5. Fuel-use penalty by vocation and RMS grade for trips with roughly net-zero elevation change

The relationship between RMS grade and fuel use also appears to vary by vocation. In Figure 6 , for example, even while accounting for both average grade and RMS grade the bus vehicle model has a higher fuel penalty curve. This increase is partially explained by average grade. While data for each vocation was downsampled to trips with absolute average grade less than $1 \%$, school bus trips skewed towards a higher absolute average grade than the other vocations.

A linear model was used to determine high-level sensitivities in the simulations and to understand the differences between vocations. The model accounted for trip characteristics (average grade, RMS grade, and average speed), vehicle characteristics (mass and engine power), and time averaged energy requirements calculated by FASTSim (such as aerodynamic drag, rolling resistance, and acceleration). The model was fit on a subset of the original data, specifically, trips where absolute average grade was between $0.00 \%$ and $0.01 \%$ and RMS grade was between $1.0 \%$ and $1.5 \%$. This subset was chosen in an attempt to normalize for RMS grade and average grade while keeping the amount of data roughly equal for each vocation.

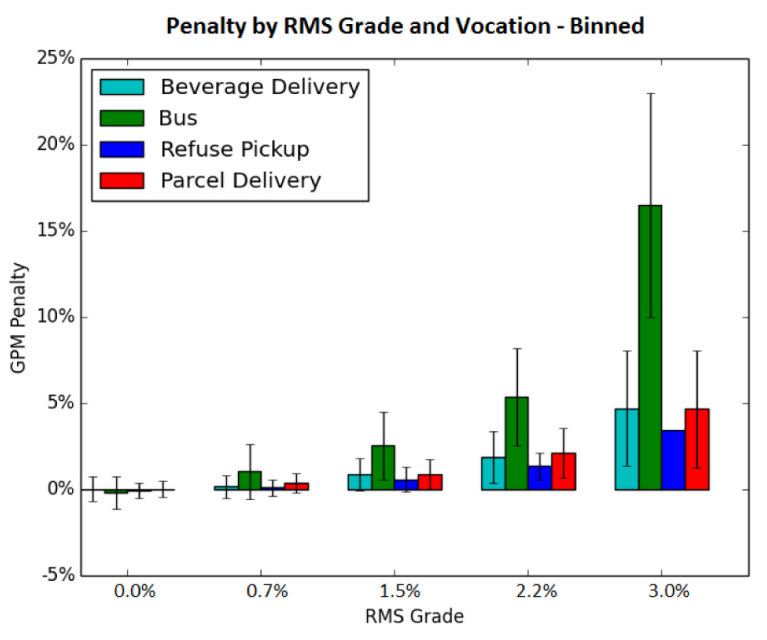

Figure 6. Fuel-use penalty by vocation and RMS grade for trips with roughly net-zero elevation change

In the linear model, each coefficient can be interpreted as the change in fuel penalty due to a change in one predictor with all else held constant. For example, the coefficient for average speed (in miles per hour) was statistically significant and had a value of 0.0002 . This implies that holding all else equal (grade, vocation, etc.) a 1-mph increase in average trip speed would increase the fuel penalty due to grade by $0.02 \%$. Using this analytical approach it was determined that mass and engine power have the largest impact on fuel penalty after accounting for grade effects. This explains the results in Figures $\underline{4}, \underline{5}$, and $\underline{6}$ because the bus vehicle model had a substantially higher curb mass and lower power than the other models (lowest power-toweight ratio at curb weight, see Table 2).

\section{Mass Study}

To further explore the impact of mass, the simulations were run for vehicle models with full payloads. In reality, the actual payload of the vehicle generating the drive cycle data is unknown. In cases where the source of the drive cycle was an empty or lighter vehicle, assuming a full payload can be problematic because the available vehicle power may be insufficient to match the trip speeds and accelerations with the heavier load. To account for this in FASTSim runs, trips with a maximum required power greater than a maximum available power (relative to vehicle model characteristics) were discarded. Table 5 summarizes the set of down-sampled drive cycles used to simulate a full payload scenario. Note that the vehicle models with the lowest power-to-weight ratios had the highest percentage of down-sampled trips. This suggests that the models with low power-to-weight ratios when empty were the most sensitive to additional weight and were most likely to be subject to vehicle performance limitations.

For comparison purposes, the down-sampled drive cycles were simulated on models with both full and empty payloads, both with and without grade data. Table 6 summarizes the results in terms of grade-induced fuel penalties (percentage increase in fuel use resulting from the inclusion of grade data in simulations). For all vocations the average grade-induced fuel use penalty increased with the increase in mass. Figure 7 shows the effect of increasing mass on fuel penalty considering different levels of RMS grade for the parcel delivery vocation. The other vocations were similar, with the higher mass corresponding to an additional increase in penalty. The variation in penalty also increases with both RMS grade and mass. 
Table 5. Summary of down-sampled vocation

\begin{tabular}{|l|l|l|l|}
\hline Vocation & $\begin{array}{l}\text { Distance of } \\
\text { All Trips } \\
(\mathrm{mi})\end{array}$ & $\begin{array}{l}\text { Distance of Trips } \\
\text { Simulated with Full } \\
\text { Payload } \\
(\mathrm{mi})\end{array}$ & $\begin{array}{l}\text { Percent Distance } \\
\text { Reduction }\end{array}$ \\
\hline Beverage Delivery & 43,371 & 22,013 & $49 \%$ \\
\hline Parcel Delivery & 14,002 & 13,516 & $4 \%$ \\
\hline Refuse Pickup & 29,931 & 27,934 & $7 \%$ \\
\hline Bus & 38,164 & 18,060 & $35 \%$ \\
\hline Total & 125,469 & 81,524 & $53 \%$ \\
\hline
\end{tabular}

Table 6. Average grade-induced fuel use penalty by vocation at vehicle curb weight and full payload weight.

\begin{tabular}{|l|l|l|l|l|}
\hline Vocation & $\begin{array}{l}\text { Avg. RMS } \\
\text { Grade }\end{array}$ & $\begin{array}{l}\text { Avg. Fuel } \\
\text { Use Penalty } \\
\text { at Curb }\end{array}$ & $\begin{array}{l}\text { Avg. Fuel } \\
\text { Use Penalty } \\
\text { at GVWR }\end{array}$ & $\begin{array}{l}\text { Difference } \\
\text { in Fuel Use } \\
\text { Penalty }\end{array}$ \\
\hline $\begin{array}{l}\text { Beverage } \\
\text { Delivery }\end{array}$ & $1.2 \%$ & $0.4 \%$ & $1.6 \%$ & $1.2 \%$ \\
\hline Parcel Delivery & $1.7 \%$ & $1.3 \%$ & $2.0 \%$ & $0.7 \%$ \\
\hline Refuse Pickup & $1.2 \%$ & $0.0 \%$ & $0.1 \%$ & $0.1 \%$ \\
\hline Bus & $2.8 \%$ & $6.1 \%$ & $8.0 \%$ & $1.9 \%$ \\
\hline
\end{tabular}

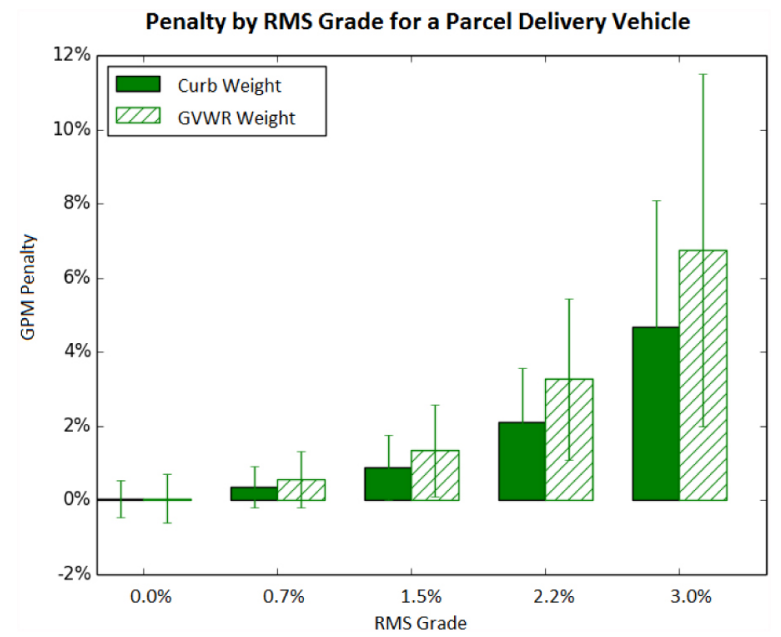

Figure 7. Fuel penalty due to grade for parcel delivery vehicles at curb weight and at GVWR weight simulated over a subset of trips with net-elevation gain close to zero.

\section{Conclusion}

The simulation results suggest that road grade contributes significantly to fuel use, with impacts ranging on average from $1 \%$ to $9 \%$ increase in fuel use. On average the penalty to ascend exceeds the benefit of descent so that trips with net-zero elevation but significant RMS grade can see fuel use increases of up to $40 \%$. The impact of grade was also shown to be sensitive to the mass/payload and vocation/vehicle scenarios. The curb weight scenario buses had a penalty averaging $10 \%$ whereas parcel delivery vehicles and beverage delivery vehicles had fuel use penalties ranging from $1 \%$ to $3 \%$. Increasing payload from curb weight to GVWR substantially increased the fuel use penalty attributed to grade in most vocations.
Overall, the simulation results suggest that grade accounts for a significant percentage of on-road fuel use in medium- and heavy-duty vehicles. Future work could include analyzing specific drive cycles to determine drive cycle characteristics, driving behavior, and vehicle model specifications that influence the sensitivity of fuel use to grade.

\section{Acknowledgments}

NREL is a national laboratory of the U.S. Department of Energy, Office of Energy Efficiency and Renewable Energy, operated by the Alliance for Sustainable Energy LLC. This work was supported by the U.S. Department of Energy under Contract No. DE-AC3608GO28308 with the National Renewable Energy Laboratory. Funding was provided by the U.S. DOE Office of Energy Efficiency and Renewable Energy Vehicle Technologies Program. The U.S. Government retains and the publisher, by accepting the article for publication, acknowledges that the U.S. Government retains a nonexclusive, paid-up, irrevocable, worldwide license to publish or reproduce the published form of this work, or allow others to do so, for U.S. Government purposes.

The authors would specifically like to thank Lee Slezak and David Anderson of the U.S. Department of Energy Vehicle Technologies Office for their support and guidance in conducting this research. Additionally, the authors like to acknowledge Evan Burton and Aaron Brooker of NREL for facilitating the use of the Fleet DNA drive cycle data and FASTSim.

\section{References}

1. U.S. Environmental Protection Agency. (February 10, 2015). "Transportation and Climate: Regulations \& Standards: HeavyDuty." Office of Transportation and Air Quality. Accessed February 16, 2015. http://www.epa.gov/otaq/climate/regsheavy-duty.htm

2. Scora, G.A., "Heavy Duty Diesel Particulate Matter and Fuel Consumption Modeling for Transportation Analysis" (PhD diss, University of California Riverside, March 2012), http:// escholarship.org/uc/item/4sj7914b

3. Franzese, O., Effect of Weight and Roadway Grade on the Fuel Economy of Class-8 Freight Trucks, Oak Ridge National Laboratory Technical Report, ORNL/TM-2011/471, October 2011, http://cta.ornl.gov/cta/Publications/Reports/ORNL TM_2011_471.pdf

4. Delorme, A., Karbowski, D., Vijayagopal, R., and Sharer, P., Evaluation of Fuel Consumption Potential of Medium and Heavy Duty Vehicles through Modeling and Simulation, Argonne National Laboratory Technical Report DEPSBEES-001 to National Academy of Sciences, October 2009. http://www.autonomie.net/docs/6\%20-\%20Papers/nas mediumheavyduty_2009.pdf

5. Ates, M. and Matthews, R., "Coastdown Coefficient Analysis of Heavy-Duty Vehicles and Application to the Examination of the Effects of Grade and Other Parameters on Fuel Consumption," SAE Technical Paper 2012-01-2051, 2012, doi:10.4271/201201-2051. 
6. Khan, A. and Clark, N., "An Empirical Approach in Determining the Effect of Road Grade on Fuel Consumption from Transit Buses," SAE Int. J. Commer. Veh. 3(1):164-180, 2010, doi:10.4271/2010-01-1950.

7. Frey, C., Zhang, K., and Rouphail, N., "Fuel Use and Emissions Comparison for Alternative Routes, Time of Day, Road Grade, and Vehicles Based on In-Use Measurements," Environ. Sci. and Technol. 42(7):2483-2489, 2008, doi:10.1021/es702493v

8. Walkowicz, K., Kelly, K., Duran, A., and Burton, E., (2014). Fleet DNA Project Data. National Renewable Energy Laboratory. http://www.nrel.gov/fleetdna

9. Duran, A. and Earleywine, M., "GPS Data Filtration Method for Drive Cycle Analysis Applications," SAE Technical Paper 2012-01-0743, 2012, doi:10.4271/2012-01-0743.

10. Wood, E., Burton, E., Duran, A., Gonder, J., et al., Appending High Resolution Elevation Data to GPS Speed Traces for Vehicle Energy Modeling and Simulation, National Renewable Energy Laboratory, June 2014, Technical Report NREL/TP5400-61109, http://www.nrel.gov/docs/fy14osti/61109.pdf.

11. NREL's Future Automotive Systems Technology Simulator (FASTSim), 2015, available online at www.nrel.gov/ transportation/fastsim.html

12. Brooker, A., Gonder, J., Wang, L., Wood, E. et al., "FASTSim: A Model to Estimate Vehicle Efficiency, Cost and Performance," SAE Technical Paper 2015-01-0973, 2015, doi:10.4271/201501-0973.

\section{Contact}

Transportation and Hydrogen Systems Center

National Renewable Energy Laboratory

15013 Denver West Pkwy MS 1634

Golden, CO 80401

Sean Lopp

(303) 275-4549

Sean.Lopp@nrel.gov

Adam Duran

(303) 275-4586

Adam.Duran@nrel.gov

Eric Wood

(303) 275-3290

Eric.Wood@nrel.gov

\section{Definitions/Abbreviations}

DEM - digital elevation model

FASTSim - Future Automotive Systems Technology Simulator

GPS - global positioning system

GVWR - gross vehicle weight rating

HHDDT - Heavy Heavy-Duty Diesel Truck schedule

NREL - National Renewable Energy Laboratory

RMS - root mean square

USGS - United States Geological Survey

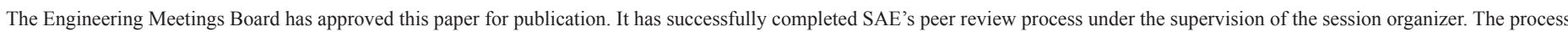
requires a minimum of three (3) reviews by industry experts.

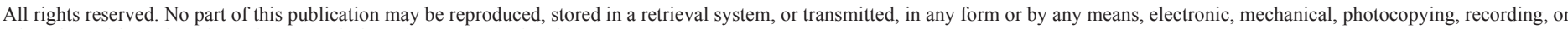
otherwise, without the prior written permission of SAE International.

Positions and opinions advanced in this paper are those of the author(s) and not necessarily those of SAE International. The author is solely responsible for the content of the paper.

ISSN 0148-7191

http://papers.sae.org/2015-01-2739 